\title{
VARIATIONS IN FOETAL WEIGHT AND VASCULAR SUPPLY ALONG THE UTERINE HORN OF THE PIG
}

\author{
J. S. PERRY AND J. G. ROWELL \\ A.R.C. Institute of Animal Physiology, Babraham, Cambridge, and \\ A.R.C. Statistics Group, School of Agriculture, University of Cambridge
}

(Received 17th January 1969)

\begin{abstract}
Summary. Weights of foetuses in ninety pigs were studied in relation to their positions in the uterine horn. Position had no effect when there were some five or fewer foetuses in the horn but as the number increased, those at the ends tended to have an increasing advantage over those in the middle and the foetus at the ovarian end tended to have an increasing advantage over the foetus at the cervical end. Percentage differences in foetal weight were substantially constant over the period of the pregnancy studied, namely 31 to 113 days after conception. Differences in foetal weight between positions could not be explained in terms of the uterine vascular architecture.
\end{abstract}

\section{INTRODUCTION}

The growth of a foetus has been shown to depend on its position in the uterine horn. This has been demonstrated in rabbits (Rosahn \& Greene, 1936), mice (McLaren \& Michie, 1959; McLaren, 1965), guinea-pigs (Ibsen, 1928) and pigs (Waldorf, Foote, Self, Chapman \& Casida, 1957). In all cases, there is a decline in foetal weight from the ovarian end towards the middle of the horn but there are considerable differences between species in the change in foetal weight between the middle of the horn and the cervical end.

The main purposes of the present investigation were to study variations in foetal weight along the uterine horn of the pig, whether these change during the course of the pregnancy, how they are affected by the number of foetuses in the horn, and whether differences in weight can be explained in terms of vascular supply.

\section{MATERIALLS AND METHODS}

\section{Experimental}

The data were derived from two sources. The first was from information supplied by Dr R. W. Pomeroy (quoted in Pomeroy, 1960) relating to sixtythree pigs, mostly sows of Large White and Essex origin, which were slaughtered at various times after conception, the dates of which were known. The second group, consisting of twenty-seven sows, of various breeds, was made available by Messrs Sainsbury \& Sons for the removal of the uterus at slaughter; in this case, 
it was necessary to estimate the gestation age of the foetuses by their stage of development and by reference to the tables of Keibel (1897). The position, weight and sex of each foetus were recorded and, in the second series, a record was also made of the course of the arteries in the broad ligament in relation to the position of individual foetuses; placental weights were not recorded. Gestation ages varied between 31 and 113 days.

\section{Statistical}

The variable analysed was the logarithm of foetal weight since it was anticipated that percentage differences between positions would remain more constant than absolute differences as the foetuses grew, and so variabilities would be relatively more constant, thereby satisfying a requirement of the analysis of variance. Results from any horn which contained dead or very light foetuses were omitted; a foetus was defined as a runt if its weight was less than two-thirds of the average for the horn. Such foetuses were regarded as growing abnormally and not part of the population of interest. This procedure, which resulted in the omission of 55 horns out of 179 , is open to question. These foetuses may fall within the same population as the other living ones but, if this is so, the distribution of foetal weights must be skewed. Their inclusion in this analysis would not have altered the conclusions reached, but would have increased their apparent significance.

The mean difference between male $(232 \mathrm{~g})$ and female $(221 \mathrm{~g})$ foetuses was small compared with differences between foetuses of the same sex and was therefore ignored; this does not introduce any bias since the sexes were randomly distributed within the horn and the effects on residual mean squares would be trivial.

Three statistics were calculated for each horn to describe features of the relation between foetal weight and position. The first variable was the quadratic regression coefficient, referred to below as 'curvature', of the logarithm of foetal weight on the distance along the horn. These distances were not in fact measured but relative distances were deduced, assuming that the length of the horn was not affected by the number of foetuses and that it did not increase from 30 days after conception (Pomeroy, 1960); it was also assumed that, on average, the foetuses were equally spaced within the horn. The second variable was the logarithm of the ratio of the mean weights of the two end foetuses to the mean weight of the remaining foetuses. This variable is similar to curvature in that it is a measure of the extent to which foetuses in the end position are heavier than the remainder. The third variable was the logarithm of the ratio of the weight of the foetus at the ovarian end to that at the cervical end.

Each of these variables was regressed on (a) gestation age, (b) mean foetal weight for the horn and (c) the number of foetuses in the horn.

\section{RESULTS}

Degenerate foetuses and runts

Out of a total of 1027 foetuses, fifty-six $(5 \%)$ were dead, and thirty-two $(3 \%)$ were runts as defined above. Out of a total of 179 horns, 124 had no dead foe- 
tuses or runts, thirty-five had one dead foetus or runt, twelve had two, four had three, three had four and one had five; a more detailed examination of these frequencies indicates that there were more horns with at least two dead foetuses than would be expected if dead foetuses were randomly distributed among the horns. Table 1 shows that foetuses in 'crowded' horns had a smaller chance of survival than those in horns containing fewer than six foetuses. Table 2

TABLE 1

EFFECT OF NUMBER OF FOETUSES IN HORN ON PERCENTAGE DEAD AND PERCENTAGE RUNTS*

\begin{tabular}{|c|c|c|c|c|c|c|}
\hline $\begin{array}{l}\text { No. of } \\
\text { foetuses } \\
\text { in horn }\end{array}$ & $\begin{array}{c}\text { No. } \\
\text { of } \\
\text { horns }\end{array}$ & $\begin{array}{c}\text { No. } \\
\text { of } \\
\text { foetuses }\end{array}$ & $\begin{array}{l}\text { No. of } \\
\text { dead } \\
\text { foetuses }\end{array}$ & $\begin{array}{c}\% \\
\text { dead } \\
\text { foetuses }\end{array}$ & $\begin{array}{c}\text { No. } \\
\text { of } \\
\text { runts }\end{array}$ & $\%$ runts \\
\hline $\begin{array}{r}1 \\
2 \\
3 \\
4 \\
5 \\
6 \\
7 \\
8 \\
9 \\
10 \\
11\end{array}$ & $\begin{array}{r}4 \\
10 \\
15 \\
23 \\
33 \\
33 \\
18 \\
20 \\
16 \\
4 \\
3\end{array}$ & $\begin{array}{r}4 \\
20 \\
45 \\
92 \\
165 \\
198 \\
126 \\
160 \\
144 \\
40 \\
33\end{array}$ & $\begin{array}{r}0 \\
0 \\
0 \\
3 \\
2 \\
12 \\
13 \\
8 \\
15 \\
1 \\
2\end{array}$ & $\left.\begin{array}{r}0 \\
0 \\
0 \\
3 \\
1 \\
6 \\
10 \\
5 \\
10 \\
2 \\
6\end{array}\right\} \begin{array}{l} \\
7 \cdot 5 \\
76 \cdot 9\end{array}$ & $\begin{array}{l}0 \\
1 \\
2 \\
0 \\
3 \\
9 \\
3 \\
4 \\
8 \\
2 \\
0\end{array}$ & $\left.\begin{array}{l}0 \\
5 \\
4 \\
0 \\
2 \\
5 \\
2 \\
2 \\
6 \\
5 \\
0\end{array}\right\} 3.7$ \\
\hline Total & 179 & 1027 & 56 & $5 \cdot 5$ & 32 & $3 \cdot 1$ \\
\hline
\end{tabular}

* A runt is defined as a foetus with a weight less than two-thirds of the average for the horn.

Differences between the three grouped percentages were significant for $\%$ dead $(P<0.001)$ and not significant for $\%$ runts.

TABLE 2

EFFECT OF GESTATION AGE ON PERGENTAGE DEAD AND PERGENTAGE RUNTS*

\begin{tabular}{c|c|c|cc|cc}
\hline $\begin{array}{c}\text { Gestation } \\
\text { age (days) }\end{array}$ & $\begin{array}{c}\text { No. of } \\
\text { horns }\end{array}$ & $\begin{array}{c}\text { No. of } \\
\text { foetuses }\end{array}$ & $\begin{array}{c}\text { No. of dead } \\
\text { foetuses }\end{array}$ & $\begin{array}{c}\% \text { dead } \\
\text { foetuses }\end{array}$ & $\begin{array}{c}\text { No. of } \\
\text { runts }\end{array}$ & $\begin{array}{c}\% \\
\text { runts }\end{array}$ \\
\hline 31 to 49 & 22 & 141 & 8 & 6 & 3 & 2 \\
50 to 69 & 44 & 298 & 18 & 6 & 6 & 2 \\
70 to 89 & 62 & 346 & 17 & 5 & 12 & 3 \\
90 to 113 & 51 & 242 & 13 & 5 & 11 & 5 \\
Total & 179 & 1027 & 56 & $5 \cdot 5$ & 32 & $3 \cdot 1$ \\
\hline
\end{tabular}

* A runt is defined as a foetus with a weight less than two-thirds of the average for the horn.

indicates that the percentage of dead foetuses observed was substantially constant during the period from 31 to 113 days after conception. There was no suggestion that either deaths or runts tended to occur in one position rather than another. Of the 912 normal foetuses which were sexed, $48 \%$ were males and of the thirty-two runts, $41 \%$ were males; the difference between these percentages was not significant and neither differed significantly from $50 \%$. 


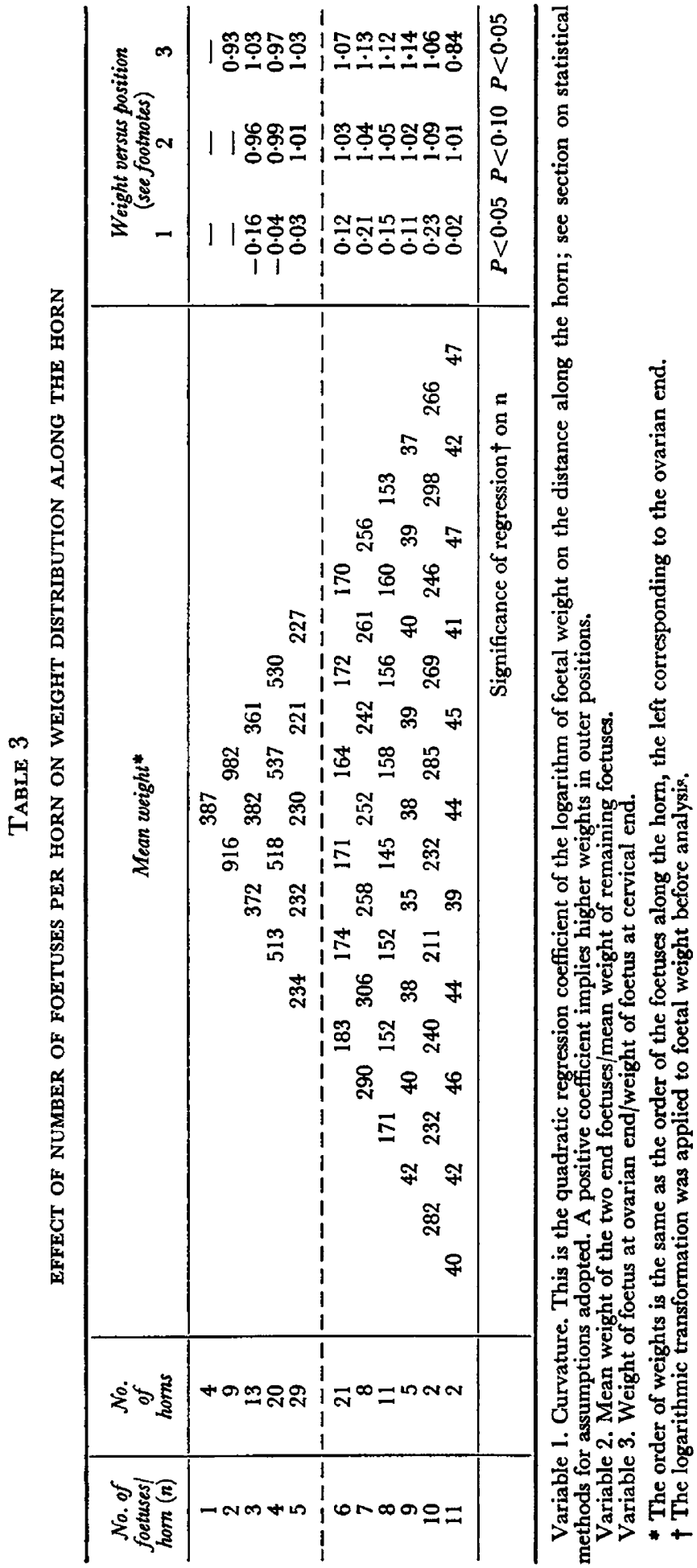


Variations in foetal weight along the horn

None of the three variables used to measure the relation between foetal weight and position (see section on statistical methods) was significantly related to either gestation age or average foetal weight for the horn. This suggests that the percentage differences between positions were maintained throughout the period of pregnancy studied ( 31 to 113 days after conception).

The effect of the number of foetuses in the horn is shown in Table 3. The analyses suggest that when there were five or fewer foetuses in the horn there was little or no difference in advantage between positions. As the numbers of foetuses in the horn increased, however, those at the ends tended to have an increasing advantage over those in the middle (up to 5 to $10 \%$ heavier) and the foetus at the ovarian end tended to have an increasing advantage over the foetus at the cervical end (up to 10 to $15 \%$ heavier). These findings indicate that when foetuses were fairly numerous, there was an increasing decline in foetal weight from the ovarian end of the horn towards the middle, associated with a slight rise in weight near the cervical end.

\section{Uterine vascular supply}

The anatomical arrangement of the blood vessels supplying the uterus of the pig is very different from that of rodents and lagomorphs. In the first place, the uterine horn itself is curved so that the ovarian and cervical ends are relatively near to each other. The border of the mesometrium, in which the uterine horn is suspended, is crenellated, so that the horn follows a sinuous course along the curved free border. The mesometrium is therefore something like a fan, of which the curved edge is strongly frilled. The main uterine artery leaves the internal iliac shortly after its origin, and is directed towards the middle of the uterine horn. It enters the mesometrium at its base and its branches diverge radially. They are usually linked by a connecting vessel that follows the curve of the uterine horn about $1 \mathrm{~cm}$ from the edge of the mesometrium. This vessel is not, as in the mouse and guinea-pig, the main uterine artery; it may have the hydrostatic action of lessening any differences of pressure in the uterine supply that might result from differences in the flow along the various radial branches.

This arrangement is very clearly shown in X-ray photographs after injection of the vessels with radiopaque material (Oxenreider, McClure \& Day, 1965). These photographs also show the manner in which the uterine blood supply is augmented by a recurrent uterine branch of the vaginal (urogenital) artery. This supplies the cervical portion of the uterine horn and often, but not invariably, has branches that anastomose with the posterior branches of the main uterine artery. Branches from the ovarian artery supply the Fallopian tube and sometimes small branches from this artery augment the branches of the main uterine artery nearest to the ovarian end of the horn.

The disposition of the major arteries is shown in plan in Text-fig. 1, which is intended to supplement the drawings presented by Oxenreider et al. (1965). In the present study, the prominence of the recurrent uterine branch has been noticed. It runs on the dorso-lateral surface of the cervix and branches in the posterior part of the mesometrium. It is evident from the size and pulse of 
this vessel that in many cases it makes a substantial contribution to the uterine blood supply during gestation. Like the main uterine artery, it increases in bore during each gestation, with considerable involution during intervening periods. The uterine branches of the ovarian artery do not enlarge to a comparable size.

The distribution of the branches of the uterine arteries in relation to the size of individual foetuses was examined in a number of specimens. A considerable degree of variation was recorded (Text-fig. 2) not only between individuals

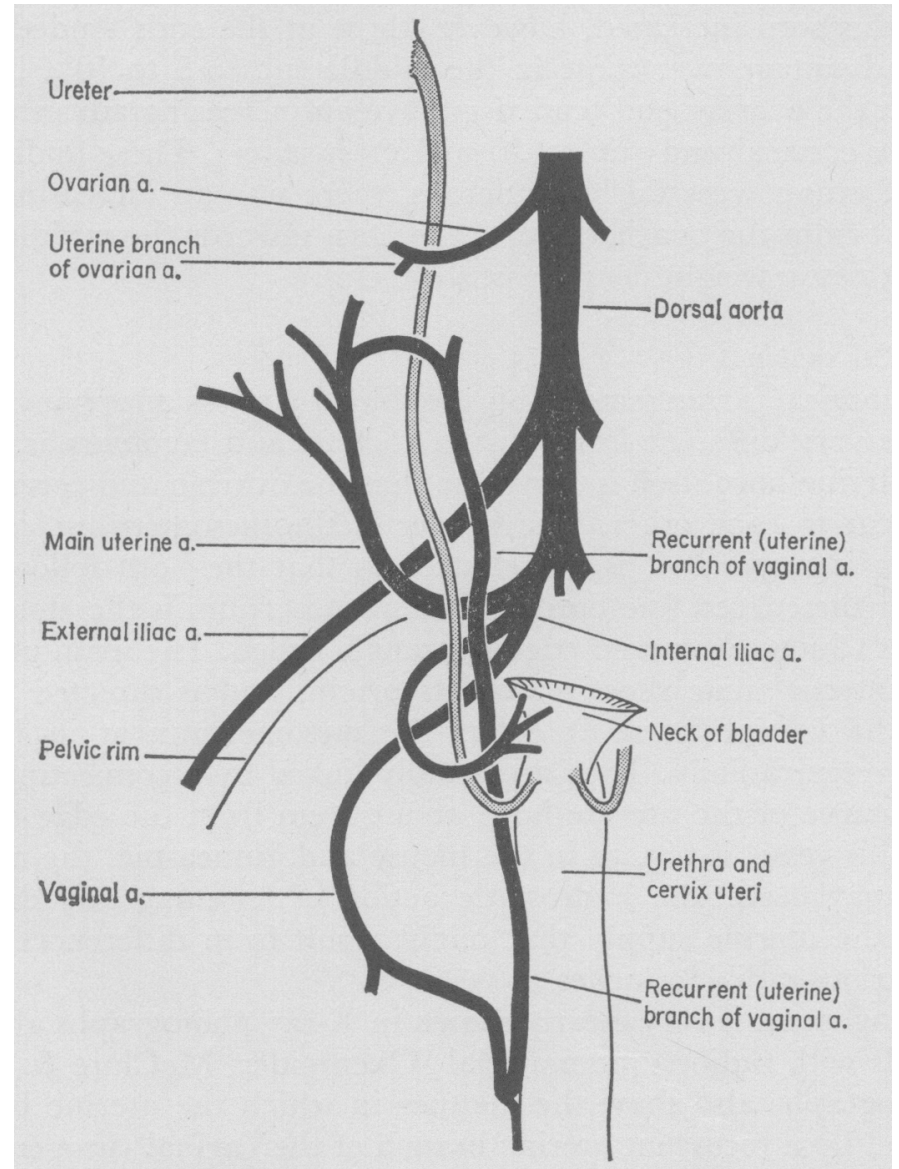

TEXT-Fig. 1. Diagram of uterine and ovarian arterial supply, from ventral aspect. The corresponding veins run near the arteries.

but, in many cases, between the left and right sides of the same animal. It proved to be quite impossible to detect, or to predict, which conceptuses would have the 'best uterine vascular contact' in terms of arterial supply or venous drainage. The largest vessels were usually those traversing the middle part of the mesometrium and extending towards the conceptuses in the middle portion of the uterine horn. The extent to which the uterine branch of the vaginal artery contributed to the total supply varied considerably and, as the diagrams show, 
the pattern of the anastomoses between the various branches varied enormously. That such variations occur very generally, in both wild and domesticated pigs, was shown by Boye (1956), who could find no correlation between the type of pattern and the age or parity of the animal. No superficially obvious relation exists between foetal weight and uterine vascular architecture in the pig. If the relation between foetal weight and uterine position is governed by haemodynamic factors in this species, the nature of these factors has yet to be explained.
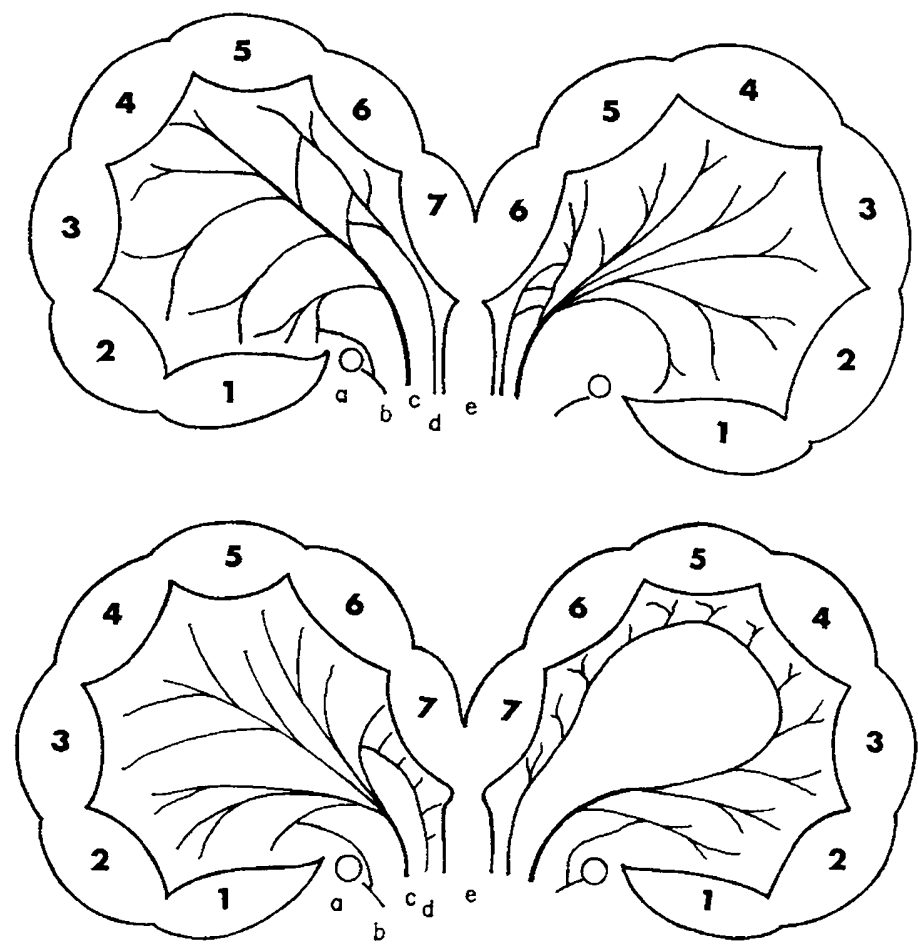

Text-F1G. 2. Different patterns of uterine arterial branches running in the mesometrium, drawn from actual specimens killed during pregnancy. The position of embryos, numbered from the ovarian end of the horn, is indicated diagrammatically: they do not occupy well-defined uterine swellings. a, ovary; b, ovarian artery; $c$, main uterine artery; d, recurrent uterine branch of vaginal artery; e, cervix.

\section{DISCUSSION}

As in the present study, Waldorf et al. (1957) found that pig foetuses at the ends of the horns were heavier than those towards the middle. Their results for gilts (primigravidae) were similar to ours but, for sows (multigravidae), differences between the two ends were not significant for foetal weight; for membrane weight the means were significantly higher at the cervical end but not at the ovarian end. Working with inbred mice, McLaren (1965) showed that the high correlation between foetal and placental weight was such that differences between positions in foetal weight could be accounted for by differences between posi- 
tions in placental growth. She found that weights decreased from the ovarian end towards the middle with little change from the middle towards the cervical end. With superovulated mice, on the other hand, (an average of 9.7 implantations per horn as against 3.9 for the untreated mice referred to above), McLaren \& Michie (1959) found a trend similar to that observed in the present study, namely a slight increase in weight from the middle of the horn towards the cervix. McLaren (1965) regarded the 'unfavourable' nature of the middle positions as strong circumstantial evidence in favour of the 'haemodynamic' theory. This theory is that the differences are due to higher blood pressure in the arterial supply at the favourable terminal sites than at the unfavourable intermediate sites. The arrangement of the uterine arterial supply in the rabbit, mouse and guinea-pig lends itself to this view. In these species, the uterine artery of each side, leaving the common iliac in the pelvic region, runs in the mesometrium, parallel with the uterine horn, which is served by lateral branches at intervals along its length; the anterior end of the artery is joined by a uterine branch of the ovarian artery, forming what McLaren (1965) described as "a system of side branches from a loop vessel fed at both ends". In such a system one might expect a pressure gradient from each end towards the middle, thus providing a possible explanation of the gradient in foetal weight. The anatomy of the uterine vascular supply of the pig, however, does not lend itself to the same explanation. Nevertheless the present data, like those for other species referred to, do suggest a 'competition' effect of some kind, in that the advantage of terminal over central positions was not clearly manifest when there were fewer than five foetuses in the horn (Table 3). The observation that the percentage positional effect did not increase with gestation age suggests that, whatever factors are involved, they operate consistently throughout pregnancy.

\section{REFERENCES}

Boye, H. (1956) Vergleichende Untersuchungen über die arterielle Gefässversorgung des Uterus von Wild- und Hausschweinen. Z. Tier zücht. ZüchtBiol. 67, 259.

Issen, H. L. (1928) Prenatal growth in guinea-pigs, with special reference to environmental factors affecting weight at birth. F. exp. Zool. 51, 51 .

KEIBEL, F. (1897) Normentafeln zur Entwicklungs geschichte der Wirbeltiere. 1. Das Schwein. Jena, 1897.

McLaren, A. (1965) Genetic and environmental effects on foetal and placental growth in mice. 7. Reprod. Fert. 9, 79.

Malaren, A. \& Mrchie, D. (1959) The spacing of implantations in the mouse uterus. Mem. Soc. Endocr. 6, 65.

Oxenremer, S. L., McClure, R. C. \& Day, B. N. (1965) Arteries and veins of the internal genitalia of female swine. 7. Reprod. Fert. 9, 19.

Pomeroy, R. W. (1960) Infertility and neonatal mortality in the sow. III. Neonatal mortality and foetal development. J. agric. Sci., Camb. 54, 31.

Rosahn, P. D. \& Greene, H. S. N. (1936) The influence of intrauterine factors on the fetal weight of rabbits. F. exp. Med. 63, 901 .

Waldorf, D. P., Foote, W. C., Self, H. L., Chapman, A. B. \& Casida, L. E. (1957) Factors affecting fetal weight late in gestation. F. Anim. Sci. 16,976. 